\title{
Haploidentical Stem Cell Transplantation with CD3+/CDI9+ ex-vivo depletion is a therapeutic option in children without a matched donor, or after graft failure: Experience at the National Institute of Pediatrics
}

\begin{abstract}
Hematopoietic stem cell transplantation is a widely used therapy for different diseases in the pediatric population. Haploidentical transplantation with negative immunoselection using electromagnetic fields is an alternative for those patients without an HLA-matched donor.

Twenty pediatric patients under 18 years old received a haploidentical CD3+/CD19+depleted transplant due to the absence of an HLA-matched donor. The mean age at which HSCT was performed was 6.6 years (range 1-18 years), and clinical indications were: acute lymphoblastic leukemia ( 9 patients), primary immunodeficiency ( 8 patients), acute myeloid leukemia ( 2 patients), and severe aplastic anemia (1 patient). The medium dose of cells infused was 10.9 (min. 2, max. 32) x 106/ $\mathrm{kg} \mathrm{CD} 34+$ cells, 3.2-4.1 x 10 $/ \mathrm{kg} \mathrm{CD3}+$ cells and 2.4-3.7 x 105/ $\mathrm{kg} \mathrm{CD19+} \mathrm{cells.} \mathrm{Results:} \mathrm{Eleven} \mathrm{of} \mathrm{the} \mathrm{twenty} \mathrm{patients} \mathrm{had} \mathrm{donor} \mathrm{engraftment}$ $(55 \%)$ and had complete chimera of their donors. From this group, nine (45\%) developed primary graft failure, and four (36\%) developed graft-versus-host disease. In the group of leukemia patients, overall survival was $75 \%$ while event-free survival was $40 \%$.
\end{abstract}

Haploidentical transplantation with negative immunoselection is a useful and feasible strategy for children without an ideal donor. In our cohort, patients with acute leukemia had better outcomes than patients with non-malignant diseases.
Volume 8 Issue 4 - 2020

\begin{abstract}
Alberto Olaya-Vargas.' Nideshda RamírezUribe,' Gerardo López-Hernández,' Haydeé Salazar-Rosales,' Ángeles del CampoMartínez,' Teresa Flores-Camacho, ${ }^{2}$ Karla Maldonado-Silva, ${ }^{2}$ Pilar Sánchez-Sánchez, ${ }^{2}$ Fabiola Mujica-Guzmán, ${ }^{3}$ Juan Carlos Bustamante-Ogando, ${ }^{4}$ Roberto Rivera-Luna ${ }^{5}$ 'Hematopoietic Stem Cell Transplantation and Cell Therapy Program, National Institute of Pediatrics (NIP), Mexico ${ }^{2}$ Blood Bank and Cell Therapy Laboratory at the NIP, Mexico ${ }^{3}$ Oncology-Hematology Laboratory at the NIP, Mexico ${ }^{4}$ Primary Immunodeficiency Research Unit at the NIP, Mexico ${ }^{5} \mathrm{Hematology-Oncology}$ Division at the NIP, Mexico
\end{abstract}

\begin{abstract}
Correspondence: Alberto Olaya-Vargas MD, Head of the Hematopoietic Stem Cell Transplantation and Cell Therapy Program, National Institute of Pediatrics (INP), Av. Insurgentes Sur 3700-C, Coyoacán, Mexico City, Mexico, Zip Code 04530, Tel 525510840900 ext. 1598,

Email alberto.olaya@yahoo.com.mx
\end{abstract}

Received: June 01, 2020 | Published: July 28, 2020
Abbreviations: LA, human leukocyte antigen; HSCT, hematopoietic stem cell transplantation; GVHD, graft-versus-host disease; HSC, hematopoietic stem cell; PCR-SSP, $\quad$ P $\quad$ C R amplification with sequence-specific primers; PBSphosphate-buffered saline; MNC, mononuclear cells; LS, large set; OS, overall survival; EFS, event-free-survival; ALL, acute lymphoblastic leukemia; AML, acute myeloid leukemia; SAA, severe aplastic; PID, primary immunodeficiencies; SCID, severe combined immunodeficiency; LAD, leukocyte-adhesion deficiency; CGD, chronic granulomatous disease; DLI, donor lymphocyte infusion

\section{Introduction}

In recent years, indications for hematopoietic stem cell transplantation (HSCT) in children have increased, and more patients are candidates to receive an HSCT. One of the main limiting factors to offer this therapy for more patients is the lack of human leukocyte antigen (HLA) -matched donors, and particularly in our country, a lack of a national donor registry. ${ }^{1-3}$ Since the 1980 s, strategies to solve this problem have been explored by obtaining cells from alternative donor sources, mostly unrelated umbilical cord blood and related haploidentical donors. ${ }^{4,5}$ Since the early 1990s, experience around the world has shown that the HLA-incompatibility barrier may be bypassed by using related donors with at least one of the two compatible Major Histocompatibility Complex haplotypes, and by increasing the dose of transplanted progenitor cells. The haploidentical transplant approach is currently accepted as an alternative for HSCT, both in children and adults who do not have an HLA-matched related or unrelated donor. ${ }^{1,6,7}$ Based on this principle, all children requiring an HSCT may have a potential donor in one of their parents. Using a haploidentical donor may condition additional risks to the patient, mainly a higher risk to develop graft-versus-host disease (GvHD).

During the last few years, many groups around the world have implemented new strategies to overcome this issue. ${ }^{1,7,8}$ Procedures used to prevent GvHD in haploidentical transplants include: in vivo T-cell depletion with post-transplant cyclophosphamide administration. ${ }^{9,10}$ ex-vivo pharmacological manipulation of the graft, ${ }^{11,12}$ use of intense immunosuppression or myeloablative conditioning regimens, ${ }^{13,14}$ and more recently ex-vivo cell manipulation with magnetic immunoselection to deplete and/or enrich the cells present in the graft before transplantation. Handgretinger et al. have shown that the positive immunoselection for CD34+ hematopoietic stem cells (HSC), offers a high possibility of engraftment and decreased the frequency of GvHD. The main disadvantage of $\mathrm{CD} 34+$ cells positive selection is an incomplete immune reconstitution after HSCT, notably in the 
B-cell compartment, which subsequently increased the probability of a leukemia relapse with loss of the graft, as well as an increased risk of post-transplant viral infections and complications, especially Epstein Barr Virus -associated lymphoproliferative disease. ${ }^{11}$

A potential strategy to overcome these problems is depleting $\mathrm{T}$ lymphocytes $(\mathrm{CD} 3+)$ and B lymphocytes $(\mathrm{CD} 19+)$ from the graft using ex-vivo negative immunoselection. This methodology maintains CD34+ HSC in the graft, as well as other immunological-competent cells like neutrophils, monocytes, and NK cells which help to achieve a faster and better immune reconstitution with less risk of infection and at the same, time reducing the risk for GvHD usually mediated by donor T-cells in the recipient tissues. ${ }^{15-18}$

Here, we report the results for a cohort of children without an HLA-matched donor who received an HSCT from haploidentical related donors after ex-vivo negative immunoselection of $\mathrm{CD} 3+$ and CD19+ cells at the National Institute of Pediatrics in Mexico.

\section{Methodology}

Twenty pediatric patients between one and eighteen years old received a haploidentical HSCT. We performed a haploidentical HSCT, as a first HSCT option, due to the lack of an HLA-matched donor $(n=16)$, or in case of primary graft failure after a previous HSCT from a cord blood unrelated donor $(n=4)$ (Table 1). All patients were assessed by our institution's HSCT and Ethics Committee. Patients and parents or guardians were informed of haploidentical transplant risks and benefits through a comprehensive process. Parents or guardians, and patients older than nine years signed an explicit letter of consent before starting the HSCT process. In the same way, the risks and benefits of the procedure was communicated to all haploidentical donors, and they were not forced at any moment to accept being a donor for HSCT. The Committee of Ethics from our institution informed the parents about the principles of confidentiality and protection of data.

Two-digit resolution HLA-compatibility tests for class I and II antigens were performed by PCR-SSP at the Hemato-Oncology laboratory. Before HSCT, all patients were assessed to rule out any organ dysfunction, and if present, to prevent further complications before, during, and after transplantation. HSCT recipients were conditioned with fludarabine $30 \mathrm{mg} / \mathrm{m} 2$ for five days, anti-thymocyte globulin $1.5 \mathrm{mg} / \mathrm{kg} /$ day for three days, one dose of total nodal radiation ( $7 \mathrm{~Gy}$ ), and melphalan $70 \mathrm{mg} / \mathrm{m} 2 /$ day for two days (Figure 1). All patients received GvHD prophylaxis with cyclosporine at doses adjusted by plasma concentration. After HSCT, serum viral loads for cytomegalovirus and Epstein Barr Virus were measured by real-time polymerase chain reaction weekly during the first six months, biweekly from six to twelve months, and monthly afterward.

HSC peripheral mobilization was obtained from all donors by using $10 \mathrm{mcg} / \mathrm{kg} / \mathrm{dose}$ of granulocyte-colony stimulating factor once a day for three days, and two doses during the fourth day. HSC were collected at the 5th day by leukapheresis (COBER 7.0 Spectra Apheresis System), and quality control studies were performed by flow cytometry (FACS CANTO, Becton Dickinson) measuring initial CD34+, CD3+ and CD19+ cell counts, as well as CD45+ cell viability, assessed by using International standard methodology (ISHAGE). After collection, the donor cells were processed immediately, $\mathrm{CD} 3+$ and $\mathrm{CD} 19+$ cells were depleted from the graft using a CliniMACS ${ }^{\circledR}$ system (Milteny Biotecbergish-Gladbach, Germany) as recommended by the manufacturer. The cells were washed twice with phosphate-buffered saline (PBS) supplemented with ethylenediaminetetraacetic acid and $0.5 \%$ human albumin followed by incubation with CliniMACS ${ }^{\circledR}$ anti-CD3 and anti-CD19 antibodies directly conjugated to magnetic microbeads. Following the manufacturer's recommendation, one vial of $\mathrm{CD} 3$ antibody was used for every $4 \times 10^{10}$ mononuclear cells (MNC) with up to $15 \times 10^{9} \mathrm{CD} 3+$ cells expected to be depleted; one vial of anti-CD19 with a maximum depletion capacity of $5 \times 10^{9} \mathrm{CD} 19+$ cells, was also used. However, since the depletion of T-cells was not as expected, the dose of antiCD3 was doubled according to the new manufacturer's instructions. The log goal for depletion was 3.0-4.1 for CD3+ and 2.2-3.7 for CD19+. Cells were under continuous agitation for 30 minutes, washed once with CliniMACS ${ }^{\circledR}$ PBS buffer, then resuspended in 150 $200 \mathrm{~mL}$ buffer solution and processed with the CliniMACS ${ }^{\circledR}$ system employing large set /tubing set and depletion tubing set separation columns for depletion using the Depletion 3.1 software. ${ }^{19}$

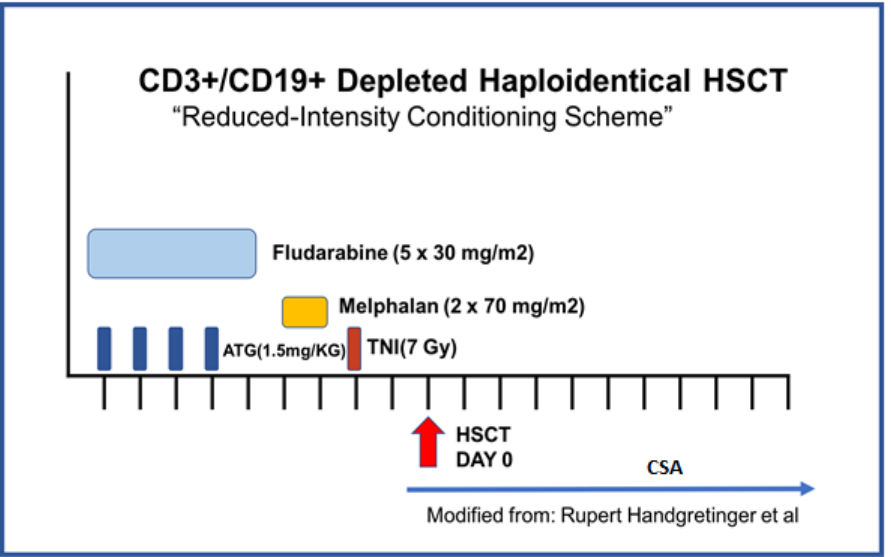

Figure I Conditioning regimen used for Haploidentical HSCT

Reduced intensity conditioning regimen for all the patients receiving haploidentical HSCT.

ATG, anti-thymocyte globulin; TNI, total nodal radiation; HSCT, hematopoietic stem cell transplantation; CsA, Cyclosporin A

When donor CD34+ cell count was suboptimal after CD3+/ CD19+ depletion, a two-step procedure was performed to enrich the final product. First, CD3+/CD19+ depletion was performed and in a second step, the negative fraction was enriched by performing a $\mathrm{CD} 34+$ positive selection, obtaining a $\mathrm{CD} 3+/ \mathrm{CD} 19+$ depleted $-\mathrm{CD} 34+$ enriched the final product for transplantation.

After HSCT, engraftment was evaluated from day three after infusion, and defined as a neutrophil count $>500$ cells $/ \mu \mathrm{L}$ for three consecutive days. Chimerism analysis post-HSCT was analyzed by phenol techniques, and chimerism was defined as complete $(\geq 95 \%)$ or partial $(\leq 95 \%)$. Post-HSCT immune reconstitution was assessed by measuring $\mathrm{CD} 3+, \mathrm{CD} 3+\mathrm{CD} 4+, \mathrm{CD} 3+\mathrm{CD} 8+, \mathrm{CD} 19+$, and $\mathrm{CD} 16+56+$ cells by flow cytometry at three, six, nine, twelve, and eighteen months post-transplant.

Descriptive statistics of epidemiologic variables was performed. A bivariate analysis was performed using Chi-Square and T student tests for qualitative variables. Overall survival (OS) and event-free survival (EFS) curves are represented using Kaplan Meier curves. Differences in OS and EFS were analyzed by the log-rank test, comparing groups based on cell dose, age, gender, paternal or maternal donor. $p<0.05$ results were considered as statistically significant. We used SPSS 20.0 program for all the statistical analyses. 


\section{Results}

Twenty pediatric patients (ten males and ten females) received a haploidentical HSCT in our Institution from 2009 to 2014. The mean age at transplantation was 6.6 years (range 1 to 18 years). Indications for HSCT were acute lymphoblastic leukemia (ALL) $(n=9)$, acute myeloid leukemia (AML) $(n=2)$, severe aplastic anemia (SAA) $(n=1)$ and primary immunodeficiencies (PID) $(n=8)$. From PID patients, four had severe combined immunodeficiency (SCID), one Griscelli syndrome, one Leukocyte-adhesion deficiency (LAD), one HyperIgM syndrome, and the remaining, chronic granulomatous disease (CGD) (Table 1). The donor was the patient's mother in seventeen transplants and the patient's father in three. The mean count of infused cells was 10.9 (min. 2, max. 32) x 10 $/ \mathrm{kg} \mathrm{CD} 34+$ cells, 3.2-4.1 x $10^{5} /$ $\mathrm{kg} \mathrm{CD} 3+$ cells and 2.4-3.7 x 105/ $\mathrm{kg} \mathrm{CD19+} \mathrm{cells.}$

The Haploidentical HSCT was used as a rescue on primary graft failure to transplantation of the umbilical cord blood in 4 patients and secondary graft failure in 4 patients. The average of the second transplant preparation time was 6.5 months (range 1-12 months).

In patients who received a CD34+ cell dose superior or equal than $10 \times 10^{6} / \mathrm{kg}$, OS was $80 \%$ while those who received less than $10^{6} / \mathrm{kg}$ showed an OS of $40 \%$, both at 40 months follow-up. The difference in OS regarding the cell dose was not statistically significant $(p=0.71)$. There was no statistical significance in the frequency of relapses related the graft's cell dose.

Figure 2A

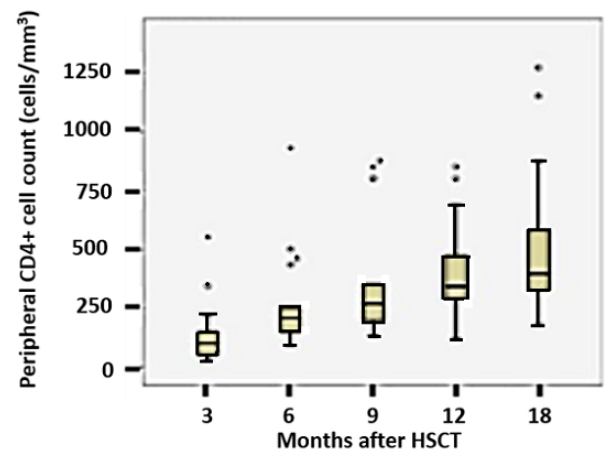

Figure 2C

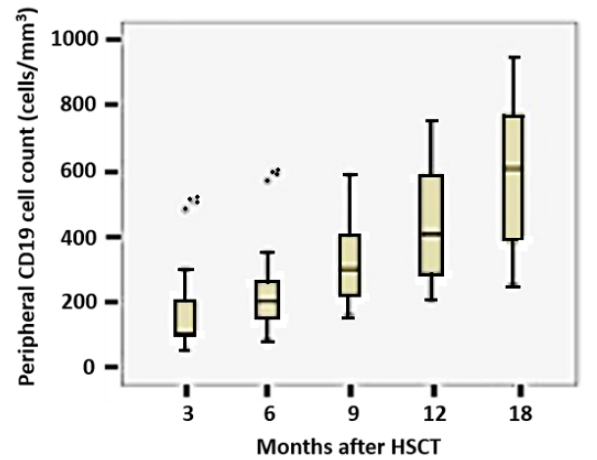

Of the twenty patients, eleven (55\%) showed engraftment with complete chimerism and nine $(45 \%)$ had primary graft failure. The Average time for myeloid engraftment was twelve days after HSCT. From the eleven patients with full chimerism, two lost their graft due to ALL relapse at four- and twelve months post-transplantation respectively, and one lost it 21 months after transplantation due to Cytomegalovirus infection. The mean hospitalization time was 35 days, ranging from 10 to 82 days (Table 1). The four patients who received haploidentical HSCT as a rescue therapy after primary graft failure from a cord blood transplant were alive and showed complete chimerism at 40-months follow up.

Of the 11 patients with complete chimerism, four developed acute GvHD grade I $(n=3)$ and grade III $(n=1)$, affecting the skin and gastrointestinal tract. None of the patients developed chronic GvHD. In the eleven patients who achieved engraftment, immunological reconstitution was assessed showing early recovery of cytotoxic T-lymphocytes $(\mathrm{CD} 3+\mathrm{CD} 8+)$ and $\mathrm{NK}$ cells $(\mathrm{CD} 16+\mathrm{CD} 56+)$ cell counts from the first evaluation at three months after HSCT in all patients. T- Helper lymphocytes $(\mathrm{CD} 3+\mathrm{CD} 4+)$ cell counts achieved the normal range between six and nine months post-transplantation. CD4+/CD8+ ratio was 0.6-1.0 at three months post-transplant and 1.21.8 at twelve months. B-lymphocytes (CD19+) cells count increased progressively from six to twelve months post-transplant, however, immunoglobulin levels in serum were low at six months after HSTC in $8 / 11$ patients, and the time to achieve normal levels was variable (Figures 2A-2C).

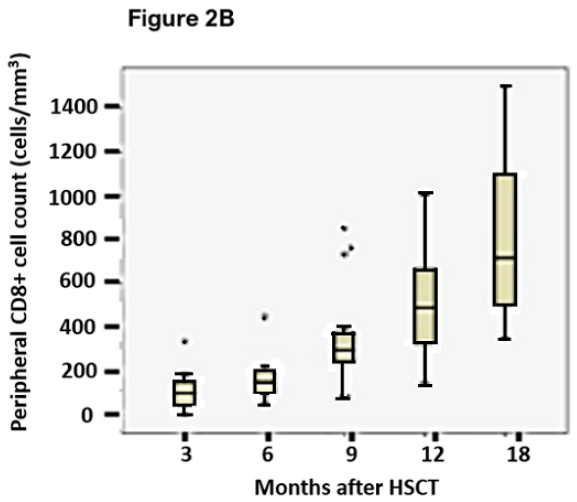

Figure 2 Immune Reconstitution after Haploidentical HSCT

Follow-up after haploidentical HSCT with CD3+/CDI9+ ex-vivo depletion in 13 patients who engrafted, shows immune reconstitution at 3, 6, 9, I 2 and I8 months post-transplantation: $2 \mathrm{~A}$ shows total CD4+ cell count (cells $/ \mathrm{mm}^{3}$ ), 2B shows total CD8+ cell count (cells/mm ${ }^{3}$ ), and $2 \mathrm{C}$ shows total CDI9+ cell count (cells $/ \mathrm{mm}^{3}$ ) in peripheral blood.Values for median (central line), lower and upper quartile ranges (box), minimum and maximum (whiskers) are represented. 
Table I Patients submitted toHaploidentical HSCT

\begin{tabular}{|c|c|c|c|c|c|c|c|c|c|c|}
\hline Patient & Gender & $\begin{array}{l}\text { Age } \\
\text { (years) }\end{array}$ & $\begin{array}{l}\text { Diagnosis at } \\
\text { HSCT }\end{array}$ & $\begin{array}{l}\text { 2nd HSCT } \\
\text { after UCB }\end{array}$ & $\begin{array}{l}\text { aGvHD } \\
\text { (Organ- } \\
\text { Grade) }\end{array}$ & $\begin{array}{l}\text { cGVHD } \\
\text { (Organ- } \\
\text { Grade) }\end{array}$ & Currentstatus & Deadcause & $\begin{array}{l}\text { Follow-up } \\
\text { (months) }\end{array}$ & DLI \\
\hline 1 & $\mathrm{~F}$ & 10 & AML, 3rd CR & Yes (I2) & No & No & Relapse & - & 40 & - \\
\hline 2 & M & I & $\begin{array}{l}\text { SCID + } \\
\text { OmenSyndrome }\end{array}$ & No & No & No & Deceased & $\begin{array}{l}\text { Relapse/ } \\
\text { Sepsis (I) }\end{array}$ & - & - \\
\hline 3 & $\mathrm{~F}$ & I & ALL, 4th CR & No & No & No & Deceased & $\begin{array}{l}\text { Relapse/ } \\
\text { Sepsis (I) }\end{array}$ & - & - \\
\hline 4 & $M$ & 2 & SCID & Yes (7) & No & No & Relapse (2I) & - & 35 & - \\
\hline 5 & M & 4 & ALL, 3rd CR & No & No & No & Deceased & $\begin{array}{l}\text { Relapse/IC } \\
\text { Bleeding (4) }\end{array}$ & - & - \\
\hline 6 & $\mathrm{~F}$ & 8 & ALL, 3rd CR & No & No & No & Relapse & - & 27 & - \\
\hline 7 & M & 3 & ALL, 3rd CR & No & No & No & Deceased & $\begin{array}{l}\text { Relapse/ } \\
\text { Zygomicosis } \\
\text { (3) }\end{array}$ & - & - \\
\hline 8 & $\mathrm{~F}$ & I & GriscelliSyndrome & No & No & No & Deceased & $\begin{array}{l}\text { B Lymphoma/ } \\
\text { Sepsis }\end{array}$ & - & - \\
\hline 9 & $M$ & 3 & ALL, 5th CR & Yes (I) & GI-III/Skin-II & Lung & Relapse & - & 13 & Yes \\
\hline 10 & $\mathrm{~F}$ & II & $\mathrm{AA}$ & Yes (II) & No & No & $\begin{array}{l}\text { Alive/ } \\
\text { GraftFailure }\end{array}$ & - & 19 & - \\
\hline II & $\mathrm{F}$ & 12 & ALL, 3rd CR & UCB + Haplo & No & No & Deceased & Relapse & - & - \\
\hline 12 & $\mathrm{~F}$ & 4 & ALL, 5th CR & Yes (2) & No & No & $\begin{array}{l}\text { Alive/ } \\
\text { GraftFailure }\end{array}$ & - & 10 & - \\
\hline 13 & $M$ & 2 & LAD & Yes (I0) & No & No & $\begin{array}{l}\text { Alive/ } \\
\text { GraftFailure }\end{array}$ & - & 10 & Yes \\
\hline 14 & $M$ & 8 & $\begin{array}{l}\text { Hyper- } \\
\text { IgMSyndrome }\end{array}$ & UCB + Haplo & No & No & $\begin{array}{l}\text { Alive/ } \\
\text { GraftFailure }\end{array}$ & - & 9 & - \\
\hline 15 & $\mathrm{~F}$ & 2 & SCID & Yes (9) & GI-III/Skin-II & No & $\begin{array}{l}\text { Alive/ } \\
\text { GraftFailure }\end{array}$ & - & 9 & Yes \\
\hline 16 & $M$ & 13 & ALL, 3rd CR & No & GI-III/Skin-II & No & Relapse & - & 7 & Yes \\
\hline 17 & $M$ & I & SCID & UCB + Haplo & No & No & Relapse & - & 4 & - \\
\hline 18 & $\mathrm{~F}$ & 6 & AML, 3rd CR & No & No & No & $\begin{array}{l}\text { Alive/ } \\
\text { GraftFailure }\end{array}$ & - & 4 & - \\
\hline 19 & $M$ & 16 & ALL, 4th CR & Yes (2) & No & No & Relapse & - & 3 & - \\
\hline 20 & $\mathrm{~F}$ & 6 & CGD & No & No & No & Alive & - & 4 & - \\
\hline
\end{tabular}

UCB, umbilical cordblood; DLI, donorlymphocyteinfusion; aGvHD, acutegraft versus host disease, cGvHD, chronicgraft versus host disease; HSCT, hematopoieticstemcelltransplantation; F, female; M, male; AA,Aplastic Anemia,ALL, acutelymphoblasticleukemia;AML, acutemyeloidleukemia; LAD, leucocyteadhesiondeficiency; SCID, severecombinedimmunodeficiency; Haplo, haploidentical; CDG, chronicgranulomatousdisease

The OS in our cohort is $70 \%$ after 40 months of follow-up (Figure $3)$. The EFS for our patients with leukemia was $40 \%$, while in children with PID was $15 \%$ (Figure 3B). Donor lymphocyte infusion (DLI) was used in five patients with secondary graft failure using a threedose scheme with a progressive increase of cell dose. In two patients, engraftment recovery was achieved after DLI. Fourteen of the twenty patients are alive at the time of this report. Six patients died due to relapse of the malignant disease $(n=3)$, or $\operatorname{GvHD}(n=3)$. Four patients died during the immediate post-transplant period due to infections.

\section{Discussion}

Different methodologies have been implemented by multiple research groups to overcome the disparity in one haplotype of the Major Histocompatibility Complex among donor and recipient when haploidentical HSCT is performed..$^{1,7,8}$ These strategies include in-vivo $\mathrm{T}$ cell depletion with cyclophosphamide administered posttransplant, ${ }^{9,10}$ ex-vivo pharmacological manipulation of the graft, ${ }^{11,12}$ and the use of conditioning regimens that produce an intense 
immunosuppression. ${ }^{13,14}$ In our series, twenty patients without an ideal donor were treated with a haploidentical HSCT using an ex-vivo CD3+ and CD19+ depletion approach by immunoselection (CliniMacs

\section{Figure 3A}

Overall Survival in Chidren ( $\mathrm{n}=19)$ Receiving Haploidentical HSCT at National Institute of Pediatrics, México (2009 - 2012).

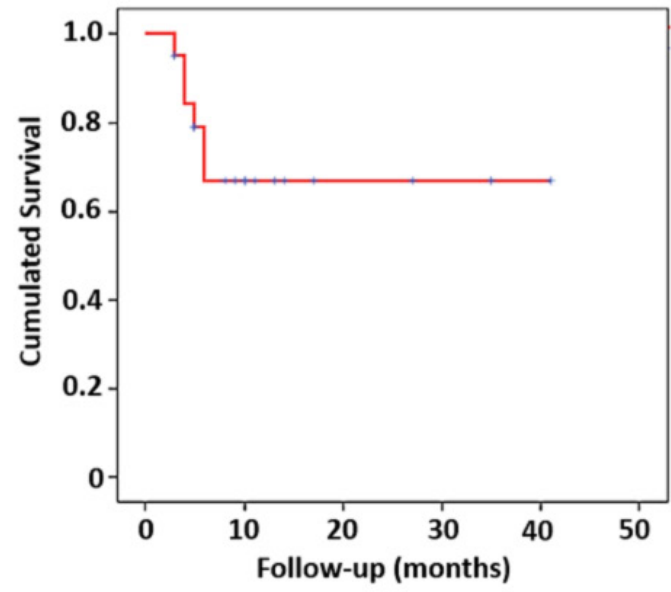

Figure $3 \mathrm{C}$

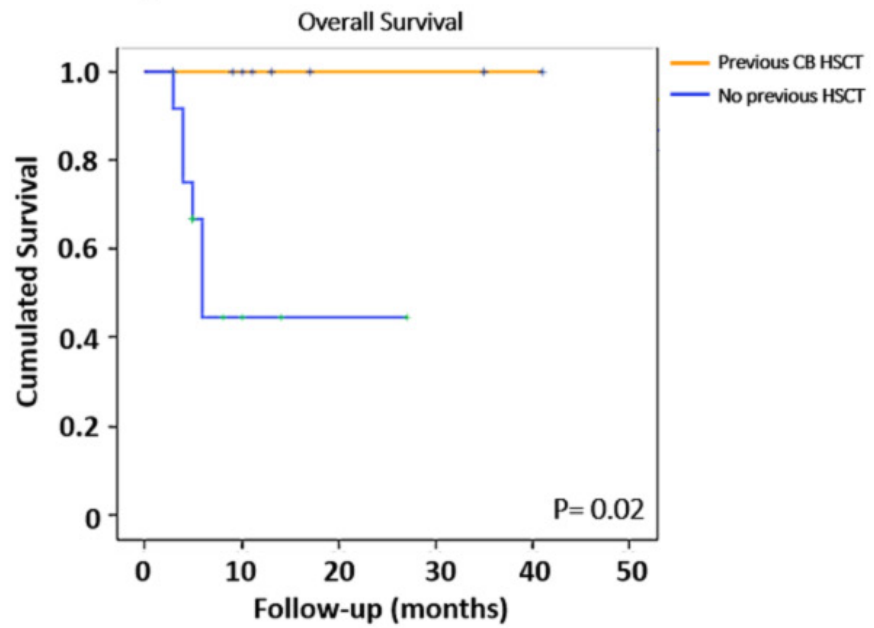

system). We achieved engraftment in eleven patients (55\%), which is similar to the results previously reported by our group, ${ }^{19}$ and slightly below to what is reported in developed countries. ${ }^{6,7}$

\section{Figure 3B}

Event-Free Survival in Chidren Receiving Haploidentical HSCT by Diagnosis.

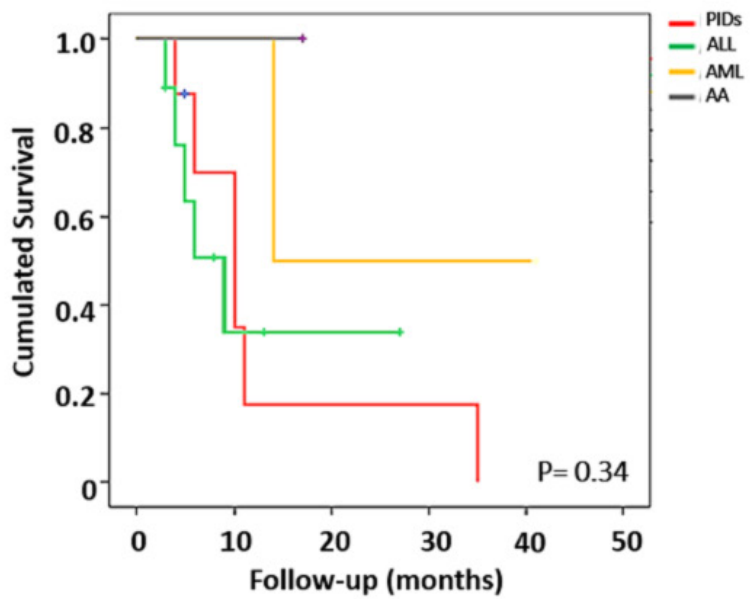

Figure 3D

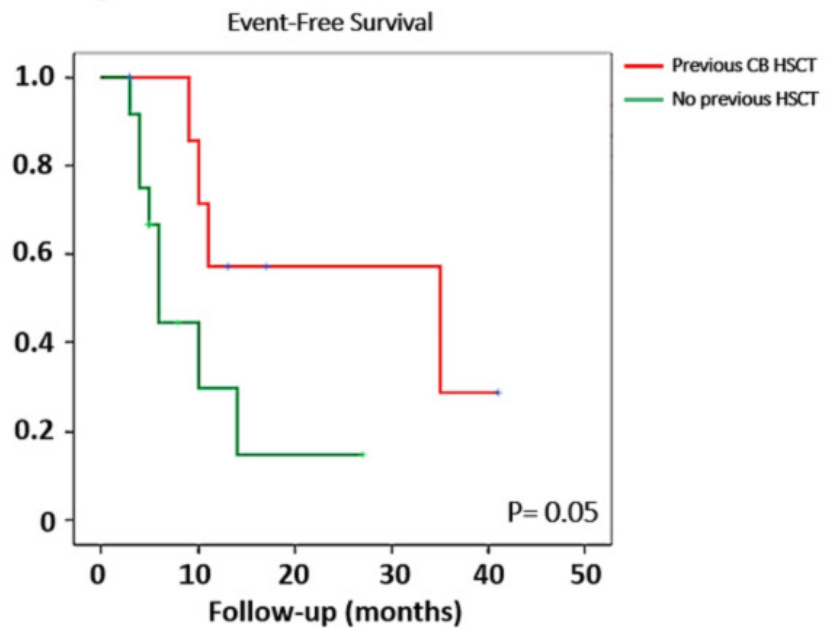

Figure 3 Overall and Free-Event Survival after Haploidentical HSCT

Kaplan-Meir plots showing: 3A Overall survival for all the patients receiving haploidentical HSCT, 3B Free-event survival by diagnosis $(A L L n=9, A M L n=2, S A A$ $n=I$, PID $n=8)$ for which haploidentical HSCT was indicated, 3C Overall survival for patients who received haploidentical HSCT with $(n=4)$ and without $(n=16)$ previous cord blood HSCT, and 3D Free-event survival for patients who received haploidentical HSCT with $(n=4)$ and without $(n=16)$ previous cord blood HSCT.

HSCT, Hematopoietic stem cell transplantation; ALL, acute lymphoblastic leukemia; AML, acute myeloid leukemia; SAA, severe aplastic anemia; PID, primary immunodeficiency

We found that primary graft failure is more frequent in patients with PID. We used CD34+ cell doses similar to what has been published in other series, ${ }^{5,21}$ and we found no statistically significant differences in OS when comparing the results based on $\mathrm{CD} 34+, \mathrm{CD} 3+$, or CD19+ cell doses. It is worth mentioning that despite higher than expected $\mathrm{CD} 3+$ cell count in the graft after the depletion, we did not observe an increase in the frequency or severity of GVHD compared to what is reported in the literature. ${ }^{6,21-23}$
It is also important to note that the use of DLI after transplantation was a useful strategy in patients undergoing haploidentical HSCT with early signs of primary graft failure, and we achieved engraftment recovery in two patients. However, in the patients who received DLI, the frequency and/or intensity of GvHD increased, as expected from what is reported in the literature. ${ }^{24}$ As we can see, our patients with primary engraftment and complete chimerism, had an early and sustained recovery of lymphocyte counts including alloreactive 
clones, which favors graft versus leukemia effect in patients with malignant disease. ${ }^{18,25,26}$ However, two patients with leukemia had post-transplantation relapse, so we highlight the relevance of determining the specificity, alloreactivity, and expression of Killer Immunoglobulin-like Receptor genes of NK cells present in the graft before transplantation, to select the ideal donor immunocompetent cells, especially in children with ALL.,27

T-cell adaptive immunity reconstitution occurred between three to nine months for the majority of our patients, ${ }^{28}$ including CD4+, CD8+ cell counts, and $\mathrm{CD} 4+/ \mathrm{CD} 8+$ ratio normalization. B-cell adaptive immunity however reconstituted slower, taking up to 12-18 months after transplantation for the complete recovery of B-cell counts and immunoglobulin production. Patients should receive antibody replacement using human immunoglobulin during this period to prevent infections.

Only $20 \%$ of patients in our series developed GvHD, mostly limited to the skin and we found a very low incidence of chronic GvHD. Coincidently with other reports, the use of $\mathrm{CD} 3+$ and $\mathrm{CD} 19+$ ex-vivo depletion diminished the risk and severity of GvHD, in comparison with other strategies used for haploidentical transplantation. ${ }^{28-30}$

The transplant-related mortality during the first 100 days posttransplant in our series was $5 \%$, which is lower than 8 and $19 \%$ previously reported by Lang and Yoshira, respectively. ${ }^{7}$ A limitation of our study is the small number of patients.

To conclude, in this report we demonstrate that haploidentical HSCT using ex vivo CD3+ and CD19+ negative selection is a feasible strategy for treatment in patients who lack an ideal donor with complete HLA-compatibility, both in patients with malignant and non-malignant diseases who require HSCT. Also, this strategy may be used as rescue therapy in patients who develop primary graft failure after a blood cord HSCT.

In places like Mexico where adequate donor registries are lacking, and many patients who require an HSCT does not have a related HLA-compatible donor, haploidentical transplant is a useful and practical strategy for treating more patients, and ex vivo immunoselection techniques offer a potential solution for the partial HLA-incompatibility and its associated complications. More efforts are needed to improve haploidentical HSCT strategies, allowing to obtain better outcomes in the future.

\section{Acknowledgments}

The authors want to thank Foundation "Aquí nadie se rinde, A.C." for the financial support to the families.

\section{Competing interests}

The authors declare no conflicts of interest associated with this manuscript, and there have been no competing financial interests for this work that could have influenced its outcome.

\section{References}

1. Klingebiel T, Cornish J, Labopin M, et al. Results and factors influencing outcome after fully haploidentical hematopoietic stem cell transplantation in children with very high-risk acute lymphoblastic leukemia: Impact of center size. Blood. 2010;115:3437-3446.

2. Marseille, France: WMDA General Membership meeting; c2017.

3. Rodríguez L, González O, Villarreal L, et al. Matched sibling donors versus alternative donors in allogeneic hematopoietic stem cell transplantation for pediatric severe aplastic anemia in México. Hematology. 2015;20(8):449-454.

4. Wang Y, Liu DH, Liu KY, et al. Long-term follow-up of haploidentical hematopoietic stem cell transplantation without in vitro $\mathrm{T}$ cell depletion for the treatment of Leukemia. Cancer. 2013;119:978-985

5. Vázquez-Meraz JE, Arellano-Galindo J, Mendoza-García E, et al. Haploidentical bone marrow transplantation in Mexico. Pediatr Blood Cancer. 2012;59(5):950-952.

6. Palma J, Salas L, Carrión F, et al. Haploidentical stem cell transplantation for children with high-risk leukemia. Pediatr Blood Cancer. 2012;59(5):895-901.

7. Lang P, Teltschik HM, Feuchtinger T, et al. Transplantation of CD3/ CD19 depleted allografts from haploidentical family donors in paediatric leukemia. Br J Haematol. 2014;165:688-698.

8. Locatelli F, Pende D, Maccario R, et al. Haploidentical hemopoietic stem cell transplantation for the treatment of high-risk leukemias: How NK cells make the difference. Clin Immunol. 2009;133(2):171-178.

9. Bolaños J, Fuchs E, Luznik L, et al. HLA-haploidentical bone marrow transplantation with posttransplant cyclophosphamide expands the donor pool for patients with sickle cell disease. Blood. 2012; 120(22):4285-4291.

10. Musetti A, Kernan NA, Prockop SE, et al. Allogeneic hematopoietic stem cell transplantation for non-malignant hematologic disorders using chemotherapy-only cytoreductive regimens and $\mathrm{T}$ cell-depleted grafts from HLA-matched or mismatched donors. Pediatr Hematol Oncol. 2016;33(6):347-358.

11. Joon-Im H, Koh KN, Jin-Seo J. Recent advances in haploidentical hematopoietic stem cell transplantation using ex vivo $\mathrm{T}$ cell-depleted graft in children and adolescents. Blood Res. 2016;51(1):-16.

12. Triplett BM, Wang C, Yang J, et al. Effects of conditioning regimens and T-cell depletion in hematopoietic cell transplantation for primary immune deficiency. Biol Blood Marrow Transplant. 2012;18 (12):1911-1920.

13. Liu DH, Zhao XS, Chang YJ, et al. The Impact of Graft Composition on Clinical Outcomes in Pediatric Patients Undergoing Unmanipulated HLA-Mismatched/Haploidentical Hematopoietic Stem Cell Transplantation. Pediatr Blood Cancer. 2011;57:135-141.

14. Munchel A, Kesserwan C, Symon HJ, et al. Nonmyeloablative HLAhaploidentical bone marrow transplantation with high dose, posttransplantation cyclophosphamide. Pediatr Rep. 2011;3(suppl2):e15.

15. Bonig H, Müller I. Feasibility of CD3/CD19 depletion of a bone marrow graft. Cytotherapy. 2016;18(10):1345-1347.

16. Goldberg JD, Zheng J, Ratan R, et al. Early recovery of T-cell function predicts improved survival after T-cell depleted allogeneic transplant. Leuk Lymphoma. 2017;58(8):1859-1871.

17. Huenecke S, Bremm M, Cappel C, et al. Optimization of individualized graft composition: CD3/CD19 depletion combined with CD34 selection for haploidentical transplantation. Transfusion. 2016;56(9):2336-2345.

18. Bader P, Sorensen J, Jarisch A, et al. Rapid immune recovery and low TRM in haploidentical stem cell transplantation in children and adolescence using CD3/CD19-depleted stem cells. Best Practice \& Research Clinical Haematology. 2011;24(3):331-337.

19. González-Llano O, Rodríguez-Romo LN, Mancías-Guerra MdelC, et al Feasibility of an outpatient HLA haploidentical stem cell transplantation program in children using a reduced-intensity conditioning regimen and CD3-CD19 depletion. Hematology. 2014;19(1):10-17. 
20. Dufort G, Pisano S, Incoronato A, et al. Feasibility and outcome of haploidentical SCT in pediatric high-risk hematologic malignancies and Fanconi anemia in Uruguay. Bone Marrow Transplant. 2012;47(5):663-668

21. Reisner Y, Hagin D, Martelli MF. Haploidentical hematopoietic transplantation: current status and future perspectives. Blood. 2011;118(23):6006-6017.

22. Schumm M, Lang P, Bethge W, et al. Depletion of T-cell receptor alpha/beta and CD19 positive cells from apheresis products with the CliniMACS device. Cytotherapy. 2013;15(10):1253-1258.

23. Handgretinger R. New Approaches to Graft Engineering for Haploidentical Bone Marrow Transplantation. Semin Oncol. 2012;39(6):664-673.

24. Park JA, Koh KN, Choi ES, et al. Successful rescue of early graft failure in pediatric patients using T-cell-depleted haploidentical hematopoietic SCT. Bone Marrow Transplant. 2014;49(2):270-275.

25. Olson JA, Leveson-Gower DB, Gill S, et al. NK cells mediate reduction of GVHD by inhibiting activated, alloreactive $\mathrm{T}$ cells while retaining GVT effects. Blood. 2010;115(21):4293-4301.
26. Anasetti C, Aversa F, Brunstein CG. Back to the Future: mismatched unrelated donor haploidentical related donor or unrelated umbilical cord blood transplantation? Biol Blood Marrow Transplant. 2012;18(1 suppl):S161-S165.

27. Pérez-Martinez A, González-Vicent M, Valentín J, et al. Early evaluation of immune reconstitution following allogeneic CD3/CD19depleted grafts from alternative donors in childhood acute leukemia. Bone Marrow Transplant. 2012;47(11):1419-1427.

28. Prezioso L, Manfra I, Bonomini S, et al. Haploidentical hematopoietic stem cell transplantation in adults using the $\alpha \beta T C R / C D 19-$ based depletion of G-CSF-mobilized peripheral blood progenitor cells. Bone Marrow Transplant. 2019;54(suppl 2):698-702.

29. Marek A, Stern M, Chalandon Y, Ansari M, Ozsahin H, Güngör $\mathrm{T}$, et al. The impact of T-cell depletion techniques on the outcome after haploidentical hematopoietic SCT. Bone Marrow Transplant. 2014;49(1):55-61.

30. Diaz MA, Pérez-Martínez A, Herrero B, et al. Prognostic factors and outcomes for pediatric patients receiving an haploidentical relative allogeneic transplant using CD3/CD19- depleted grafts. Bone Marrow Transplant. 2016;51(9):1211-1216. 